\title{
Revised Mechanism for a Ruthenium-Catalyzed Coupling of Aldehyde and Terminal Alkyne
}

\author{
Anna Tomberg, ${ }^{\dagger}$ Soumen Kundu, ${ }^{\ddagger}$ Feng Zhou, ${ }^{\S}$ Chao-Jun Li, ${ }^{*}$ (이 and Nicolas Moitessier*(i)
}

Department of Chemistry and FQRNT Centre for Green Chemistry and Catalysis, McGill University, Montréal, Quebec, Canada H3A 0B8

\section{Supporting Information}

ABSTRACT: Ruthenium catalysts have been found to be of great use for many kinds of reactions. Understanding the details of the catalytic cycle allows to not only rationalize experimental results but also to improve upon reactions. Herein, we present a detailed computational study of a ruthenium-catalyzed coupling between a terminal alkyne and an aldehyde. The reaction under examination facilitates novel access to olefins with the concurrent loss of a single carbon as carbon monoxide. The reaction was first developed in 2009, but the tentative mechanism initially proposed was proven to be contradictory to some experimental data obtained since then. Using a combination of computational investigations and isotope-labeling experiments, several potential mechanisms have been studied. In contrast to the $[2+2]$ cycloaddition mechanism suggested for similar catalysts, we propose a new consensus pathway that proceeds through the formation of a ruthenium-vinylidene complex that undergoes an aldol-type reaction with the aldehyde to yield the product olefins. Computational insights into the influence of different reagents used to optimize reaction conditions and the intricacies of decarbonylation of a $\mathrm{Ru}-\mathrm{CO}$ complex affecting catalyst turnover are highlighted.

\section{INTRODUCTION}

Coupling reactions forming carbon-carbon double bonds are some of the most important processes in organic chemistry. They have found wide application for the synthesis of electronic materials, bioactive natural products, pharmaceuticals, and feedstock for various chemical transformations. Over the years, numerous methodologies have been developed for these useful reactions. ${ }^{1-7}$ One of the most successful methods to generate $\mathrm{C}=\mathrm{C}$ bonds was discovered by Wittig and Geissler in $1953{ }^{8}$ and reacts carbonyls and phosphonium ylides to produce olefins. Wittig olefination and its complementary variations $^{9-13}$ are widely used in both industry and research laboratories. However, the use of stoichiometric amounts of ylides, rather low atom economy, and generation of phosphine oxide as a problematic byproduct has, in recent times, created economic and environmental concerns and limited this once ubiquitous process. Many of these limitations have been obviated by the discovery of catalytic Heck-type reactions, olefin metathesis protocols, and other catalytic methodologies. ${ }^{14-20}$ These reactions often use organometallic complexes to catalyze the chemical transformations because transition metals can provide efficient ways to make and break chemical bonds, sometimes between groups that would otherwise be inert. ${ }^{21}$ Ruthenium is in general an attractive transition metal to use in different kinds of catalysis due to the stability of its complexes with organic ligands in air and with respect to moisture.

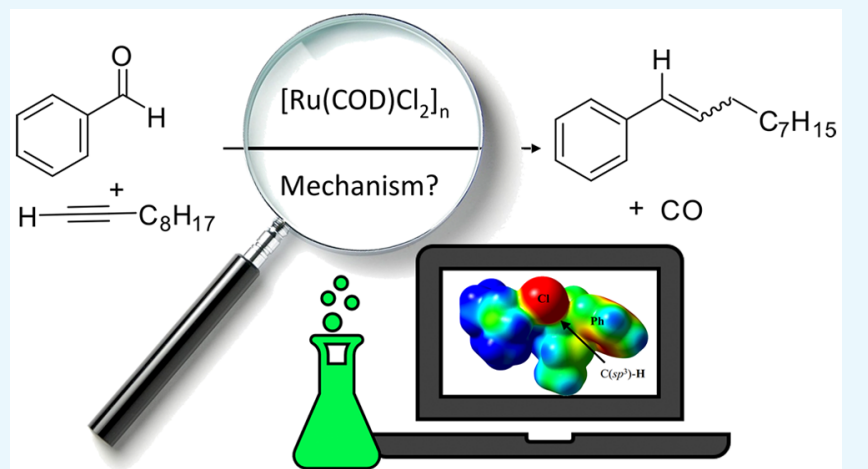

A few years back, we have reported a method for $\mathrm{C}=\mathrm{C}$ bond formation involving ruthenium-catalyzed coupling of aromatic aldehydes with terminal alkynes to produce olefins in moderate to excellent yields (Scheme $1 \mathrm{~A}){ }^{23}$ This reaction is atomeconomical (loss of only carbon monoxide), utilizes easily available starting materials, and does not require any additional activation. When suggesting a possible catalytic cycle, we based our hypotheses on previously reported mechanisms for similar catalysts. More specifically, inspired by numerous reports on ruthenium-catalyzed hydroacylation reactions resulting in acylhydrido-ruthenium complexes, ${ }^{24-27}$ decarbonylation of aldehydes, ${ }^{28,29}$ and migratory insertion of nucleophiles to ruthenium bound alkynes, ${ }^{22,30-33}$ we proposed that a decarbonylative addition mechanism is at play (Scheme 1B). In that tentative mechanism, the key elementary steps are oxidative addition of $\mathrm{Ru}^{\mathrm{II}}$ to the aromatic aldehyde $\mathrm{C}-\mathrm{H}$ bond to form a $\mathrm{Ru}^{\mathrm{IV}}$-acyl intermediate, decarbonylation of $\mathrm{Ru}^{\mathrm{IV}}$-acyl complex to form a $(\mathrm{CO}) \mathrm{Ru}^{\mathrm{IV}}$-aryl complex, and migratory insertion of the aryl group to the metal bound alkyne terminal carbon. ${ }^{23}$ There are several examples of late transition metal catalyzed aldehyde $\mathrm{C}-\mathrm{H}$ activation, followed by the formation of the metal hydrido-acyl species that are participating in migratory insertion into a $\mathrm{C}=\mathrm{C}$ bond to ultimately generate a

Received: November 28, 2017

Accepted: February 28, 2018

Published: March 16, 2018 
Scheme 1. Ruthenium-Catalyzed (A) Coupling of Aromatic Aldehydes and Terminal Alkynes To Form Olefins, Using Optimized Conditions ${ }^{23}$ and (B) Tentative Reaction Mechanism Proposed Previously

(A)
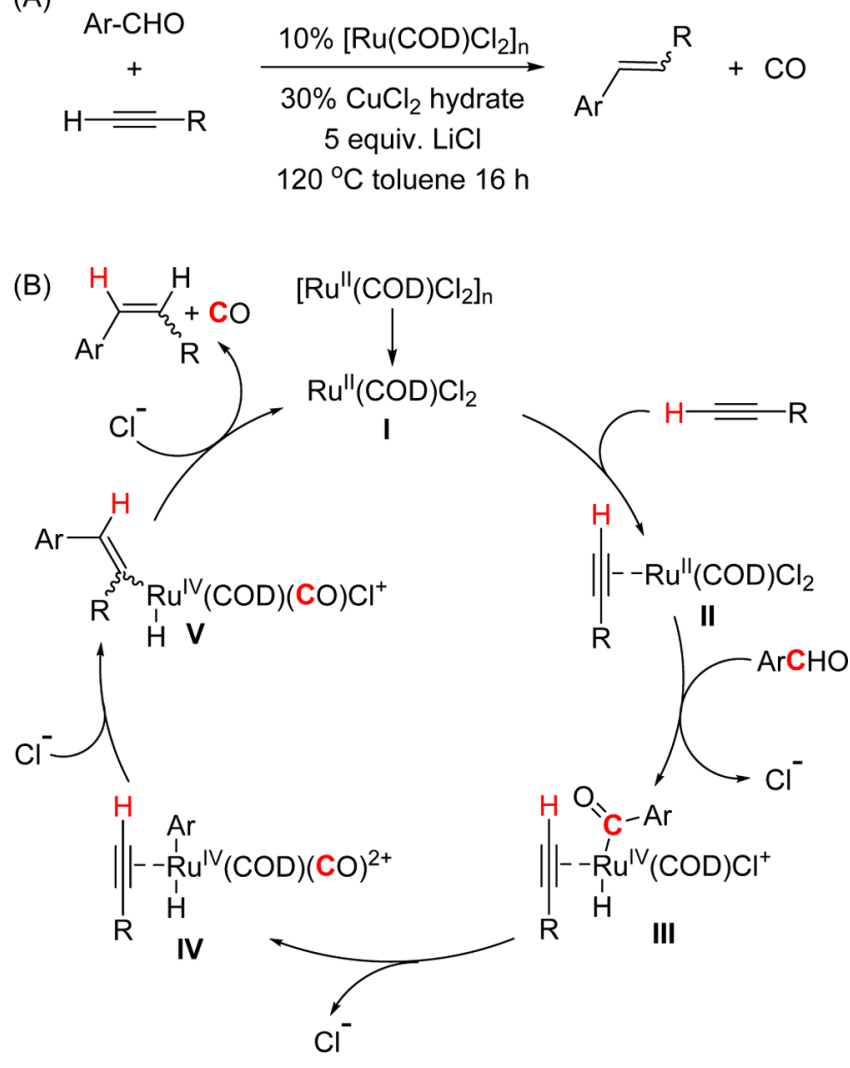

ketone $e^{34-37}$ or undergoing reductive decarbonylation to generate saturated $\mathrm{C}-\mathrm{C}$ bonds ( $\mathrm{RCHO}$ to $\mathrm{R}-\mathrm{R}$ ) or $\mathrm{C}-\mathrm{H}$ bonds $(\mathrm{RCHO}$ to $\mathrm{R}-\mathrm{H}){ }^{38-40}$ In addition, we developed a rhodium-catalyzed coupling of aromatic aldehyde to norbornene to form a saturated $\mathrm{C}-\mathrm{C}$ bond, ${ }^{41}$ where the reaction was shown to proceed via aldehyde decarbonylation.

Other groups, working with similar catalysts, have proposed other mechanisms for this type of coupling reaction. Saá and co-workers developed an intramolecular version (Scheme 2A) with a ruthenium-catalyzed and Brønsted acid-promoted cyclization of terminal alkynals to cycloalkenes. ${ }^{42}$ It was proposed that the reaction proceeds through the formation of a ruthenium-vinylidene species, which follows an aldol-type reaction to generate the final cycloalkene product (Scheme 2B). In a related computational study, Zhang et al. have suggested that the reaction, shown in Scheme 2A, proceeds through the formation of a four-membered ring (Scheme 2C). ${ }^{43}$ The mechanism was further supported by the isolation of an osmium oxetylidene complex (Figure 2D) by Esteruelas and co-workers a few years later as key intermediate in a similar intramolecular coupling. ${ }^{44}$ Interestingly, the corresponding ruthenium complex has not yet been isolated, but a detailed mechanistic study leading to a catalytic cycle featuring this intermediate has been reported. ${ }^{45}$ These differences between the intra- and intermolecular olefination reaction mechanisms have created a debate, addressed in a highlight by Allen and Williams. ${ }^{46}$ In the intramolecular reaction, the terminal carbon of the alkyne is lost as $\mathrm{CO}$ (Scheme $2 \mathrm{~B}$ ), whereas our tentative intermolecular reaction mechanism instead dictates the loss of
Scheme 2. (A) Ruthenium-Catalyzed Cyclization of Terminal Alkynals to Cycloalkenes, ${ }^{a 42}$ (B) Proposed Mechanism for (A) by Saá, (C) Proposed Mechanism for (A) by Zhang, and (D) Complexes Isolated by Esteruelas, Saá and Co-workers 44,45

(A)

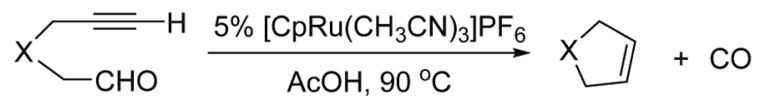

$\mathrm{X}=\mathrm{C}\left(\mathrm{CO}_{2} \mathrm{Me}\right)_{2}, \mathrm{C}\left(\mathrm{CH}_{2} \mathrm{OR}\right)_{2}, \mathrm{NTs}$, etc

(B)

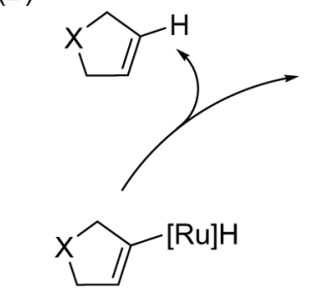

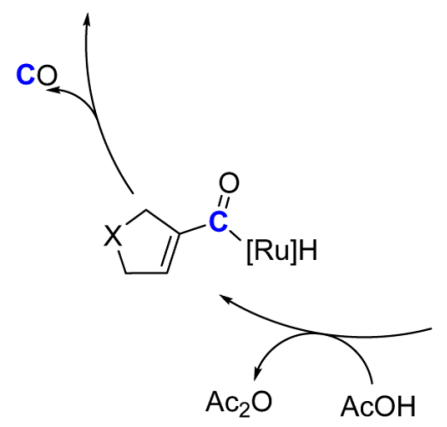<smiles></smiles>

(C)<smiles>[X]CC(=O)CC(C)C(C)CN(C)C#C</smiles>

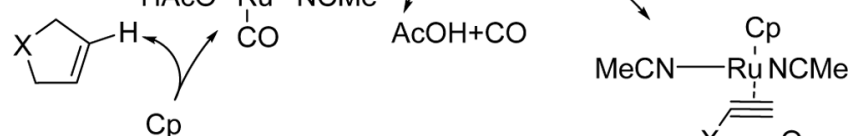

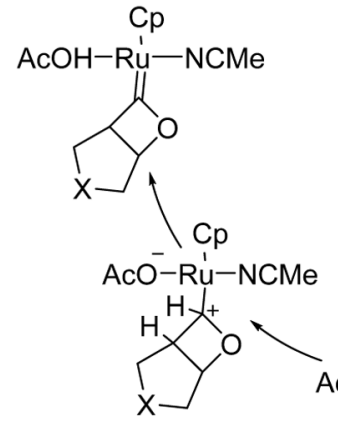

(D)
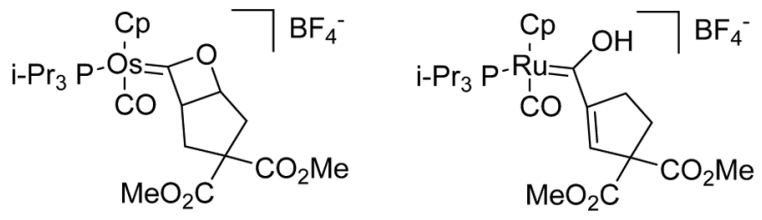

${ }^{a}$ Five- and six-member rings, only five-member shown in the scheme. 
aldehyde-originating CO (Scheme 1B). It should be noted that the conditions employed for both reactions are markedly different, which makes alternate operational mechanisms entirely plausible. In fact, the catalytic system for the intramolecular reaction does not produce any corresponding olefination product for the intermolecular reaction. Furthermore, the reactions explored by Saá and co-workers were carried out without water, whereas the corresponding intermolecular coupling requires small amounts of water.

To reconcile the mechanistic differences, and to further develop this olefination into a more applicable synthetic tool, a detailed computational investigation of the reaction mechanism using quantum chemical methods was undertaken. To support the modeling, isotope-labeling studies as well as control experiments were carried out. In this contribution, we present (i) the rationale and (ii) computational insights into the reaction mechanisms, reaction stereoselectivity, importance of singlet and triplet ruthenium spin states, and intricacies of decarbonylation of a $\mathrm{Ru}-\mathrm{CO}$ complex affecting the catalyst turnover.

\section{RESULTS AND DISCUSSION}

Testing our Proposed Mechanism. The tentative mechanism we previously proposed ${ }^{23}$ (Scheme $1 \mathrm{~B}$ ) is initiated by the formation of the active monomeric catalyst (I) from the polymeric starting material. This step is followed by the coordination of the alkyne to the metal, forming intermediate II. The next step proceeds through the oxidative addition of the $\mathrm{Ru}^{\mathrm{II}}$ to the aldehyde $\mathrm{C}-\mathrm{H}$ bond to form intermediate III. The subsequent decarbonylation of the $\mathrm{Ru}^{\mathrm{IV}}$-acyl complex forms intermediate $\mathbf{I V}$, which then collapses to $\mathbf{V}$ by a migratory insertion of the aryl group to the alkyne terminal carbon. The final step proceeds through a reductive elimination to generate the product. According to this mechanism, both alkyne sp carbons are conserved in the product olefin and the aldehyde acyl carbon is lost as CO (marked in red on Scheme 1B).

To test this hypothesis, we used the reagents that cannot undergo all of the proposed reaction steps. For example, the first productive step is the oxidative addition of the ruthenium complex to the aldehyde $\mathrm{C}-\mathrm{H}$ bond. Thus, the reaction should not lead to a product if a ketone is used instead of an aldehyde. However, upon reacting acetophenone with 1-decyne (under previously optimized conditions) produced the trisubstituted olefin $((E$ and $Z)$-undec-2-en-2-ylbenzene) in $10 \%$ yield with $15 \%$ conversion of the ketone (Scheme $3 \mathrm{~A})$. This experiment confirmed that the presence of an aldehyde $\mathrm{C}-\mathrm{H}$ was not required for the success of the reaction and that the reaction most likely does not proceed through the oxidative addition

Scheme 3. (A) Reaction of Acetophenone with 1-Decyne and (B) Reaction of 4-Anisaldehyde without 1-Decyne, Using Optimized Conditions ${ }^{23}$

(A)

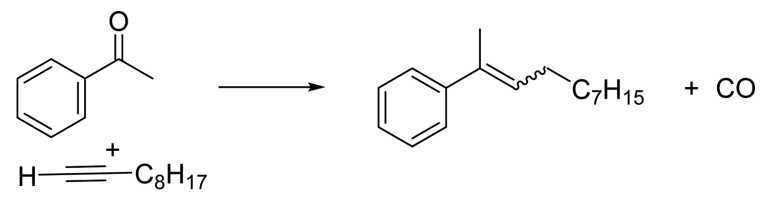

(B)

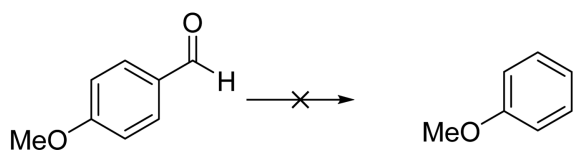

step (II-III). It is worth noting that trisubstituted alkenes are valuable synthetic intermediate and their regio- and stereoselective synthesis is generally accepted to be more challenging than that of mono- and disubstituted alkenes. ${ }^{13,47}$

According to the proposed mechanism in Scheme 1B, the aldehyde initiates the reaction (formation of III and IV) through oxidative addition of the $\mathrm{Ru}^{\mathrm{II}}$ to the aldehyde $\mathrm{C}-\mathrm{H}$ bond and subsequent decarbonylation of the $\mathrm{Ru}^{\mathrm{IV}}-\mathrm{acyl}$ complex. In the absence of alkyne, a complex similar to IV can proceed through a reductive elimination step to form Ar$\mathrm{H}^{40,48}$ However, under optimized conditions, 4-anisaldehyde did not produce any detectable anisole and instead resulted in the recovery of $85 \%$ of the starting material (Scheme 3B).

Based on these experiments, it can be concluded that the reaction does not proceed through the initial activation of aldehyde and that the proposed mechanism shown in Scheme $1 \mathrm{~B}$ can be ruled out.

An Alternative Mechanism: [2+2] Cycloaddition. The mechanism similar to the one proposed by Zhang et al., ${ }^{43}$ where the critical intermediate is a ruthenium coordinated oxetane, was next investigated by computational means. As suggested by Saá and co-workers, the catalytic cycle begins after the activation of the terminal alkyne by $\mathrm{Ru}^{\mathrm{II}}$ to generate a ruthenium-vinylidene intermediate. Note that the formation of the vinylidene through a hydrogen migration onto ruthenium was found unlikely by Zhang. Alternatively, compound VI (Figure 1A) proposed here can be obtained via, for example, a direct 1,2-hydrogen migration or by a two-step process where the first step is the the oxidative addition of the alkyne sp $\mathrm{C}-\mathrm{H}$ bond to the metal and the second is the dissociative 1,3hydrogen migration, ${ }^{49-53}$ along with other bimolecular pathways. ${ }^{54,55} \mathrm{~A}$ ruthenium-vinylidene complex (VI, Figure 1B) formation, that has been previously studied, ${ }^{56}$ was used as a starting point for our modeling.

To effectively model complex VI and the subsequent steps of the reaction, the long alkane chain $\mathrm{C}_{8} \mathrm{H}_{17}$ of 1-decyne (used in all of the experiments) was reduced in size to three carbons. This reduced the computational cost while retaining the bulkiness of the structure. The ruthenium-vinylidene complex was found to have two stable conformations in a singlet spin state $5.9 \mathrm{kcal} / \mathrm{mol}$ apart: a closed one (Figure 1B) and an open one (Figure 1C, higher in energy). The next steps of the new pathway were modeled using the lowest-energy structure of complex VI (closed).

A common $[2+2]$ mode of cycloaddition of metalvinylidene complexes with unsaturated moieties involves the formation of metallacycles (via the addition to the $\mathrm{M}=\mathrm{C}_{\alpha}$ bond). ${ }^{53,57,58}$ In our case, however, this pathway cannot lead to the desired $\mathrm{C}-\mathrm{C}$ connectivity, and it was not considered. One possibility is the incorporation of the $\mathrm{C}_{\alpha}=\mathrm{C}_{\beta}$ bond in the metal-vinylidene complexes. ${ }^{53,59-63}$ Scheme 4 depicts a proposed mechanism where the first step is the $[2+2]$ cyclization between ruthenium-vinylidene and benzaldehyde to form an oxetylidene intermediate VII. Aided by water acting as an acid/base, this intermediate proceeds to form an $\alpha$ hydroxy- $\mathrm{Ru}^{\mathrm{II}}$ carbene-type intermediate (VIII), which can then undergo a keto-enol tautomerization to form an $\alpha, \beta$ unsaturated-carbonyl intermediate (IX). The intermediate IX proceeds through decarbonylation $(\mathbf{I X}-\mathbf{X})$ and reductive elimination to form the product olefins.

The formation of oxetylidene intermediate VII was modeled in both the cis and the trans configurations. This transformation might occur in a stepwise manner: first, the carbon-oxygen 


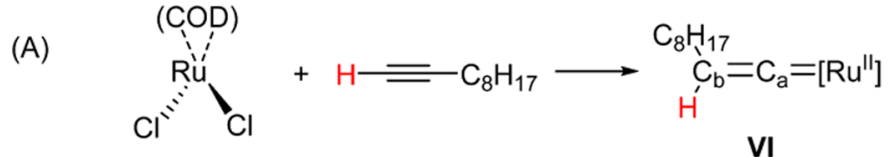
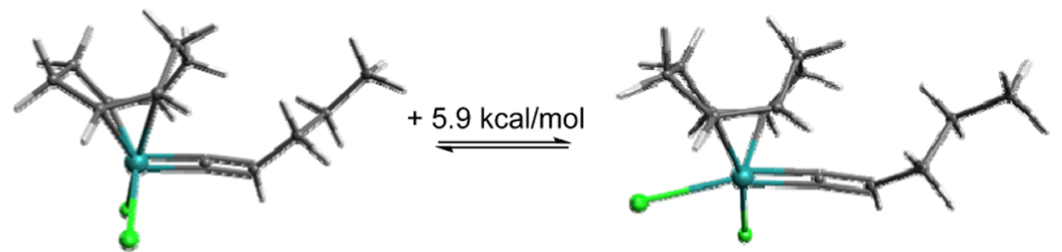

(B)

VI closed

(C) VI open

Figure 1. (A) Formation of ruthenium-vinylidene complex VI; model of complex VI in closed (B) and open (C) geometries.

Scheme 4. Proposed Mechanism for Olefin Formation through the Intermediacy of a $[2+2]$ Adduct

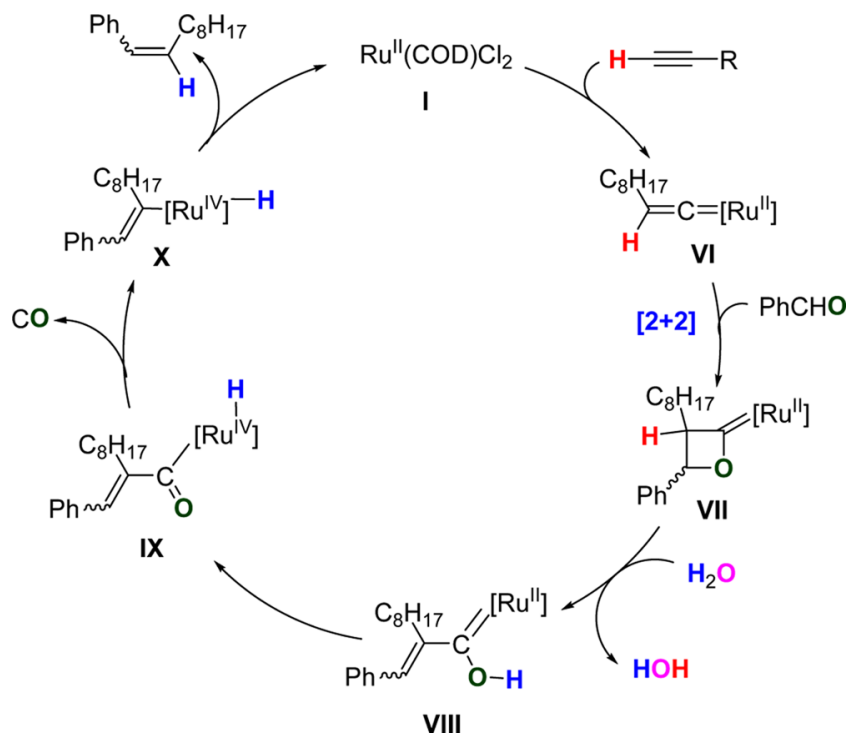

bond is formed via an edge-to-face TS, then the carbon-carbon bond forms via a second TS (as described by Zhang et al. (Scheme 2C)). However, although the energy barriers computed were not high $(15.9 \mathrm{kcal} / \mathrm{mol})$, the transition structures identified were not first-order saddle points on the potential energy surface; two imaginary frequencies corresponding to the correct bond formation were present. Moreover, the optimization of the intermediate structure resulting from the $\mathrm{C}-\mathrm{O}$ bond formation yielded an unstable molecule, which coordinated with a chloride ligand of the catalyst (Scheme 5). From there, the second step of the reaction to form a four-member ring was geometrically impossible. Although this mechanism was put forward in the literature and did not contradict the previous experimental findings (Scheme 3), the instability of the reaction intermediate necessary for the following oxygen-carbon bond formation suggests that a different pathway should be considered.

Efforts to optimize the TS were unsuccessful, so we reverted to experiments and ran a control experiment where water was replaced by methanol. In Scheme 4, water acts as an acid/base to promote the opening of the four-member cycle to produce intermediate VIII; therefore, in the presence of a molecule sharing some but not all of water's properties (acid/base and nucleophile), this mechanism is expected to slow down, yet still yielding the product. When the experiment was repeated, this
Scheme 5. $[2+2]$ Cycloaddition: Unstable Intermediate in the Formation of VII

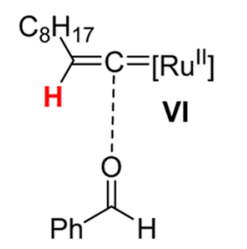
$\underset{\text { step } 1}{\stackrel{[2+2]}{\longrightarrow}}$

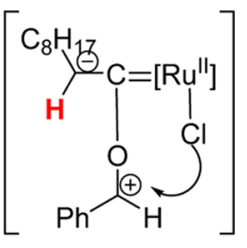

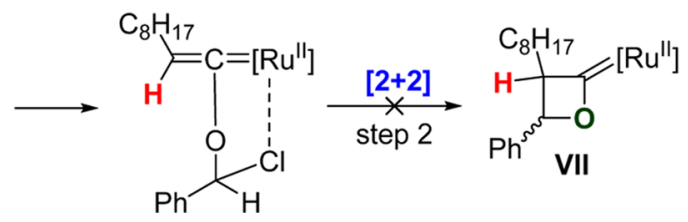

time replacing water by methanol, the product was not observed. This experimental result together with our computational observations suggests that the $[2+2]$ cycloaddition mechanism (Scheme 4) is unlikely.

An Alternative Mechanism: Aldol-type Condensation. Because the activation of the terminal alkyne by the ruthenium catalyst seemed reasonable, a second mechanism beginning with the formation of complex VI was proposed. In Scheme 6, the reaction proceeds through the hydration of the rutheniumvinylidene double bond to form a formal $\alpha$-hydroxyvinyl- $\mathrm{Ru}^{\mathrm{IV}}-$

Scheme 6. Proposed Mechanism for Olefin Formation through an Aldol-type Condensation

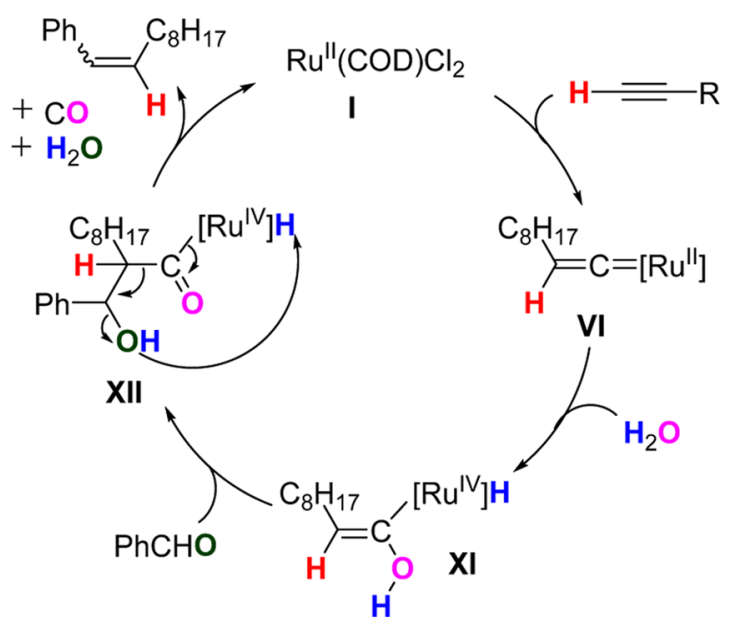


hydride species (XI). The next step consists in an aldol-type reaction between complex XI and the aldehyde to form the $\beta$ hydroxy-ketone intermediate XII. In general, rutheniumvinylidene and other late transition metal-vinylidenes are considered electrophilic in nature. Electrophilicity here is a property that is dependent on the nature of the ligands. Metalvinylidenes have been shown to participate in attack by nucleophiles on the $\mathrm{C}_{\alpha}$ (directly bonded to metal) and electrophilic attack on the $\mathrm{C}_{\beta}{ }^{42,53,64-66}$ which is in line with the mechanism proposed here. The complex XII then undergoes a reductive elimination to produce the cis- and trans-olefins, water as well as carbon monoxide to regenerate the catalyst.

Attack on metal-vinylidene complexes by water is well documented, although the exact mechanism has not been explicitly addressed: ${ }^{67-71}$ a $\alpha$-hydroxyvinyl- $\mathrm{Ru}^{\mathrm{IV}}$-hydride species similar to XI has been implicated as an intermediate during the ruthenium-catalyzed hydration of 1-alkynes to yield aldehydes. Our modeling suggests that it is in fact not one but two water molecules that are at play. Interestingly, following the coordination of one water molecule VI rearranges into its open conformation (Figure 2A). The coordination of water proceeds without a TS and stabilizes the metal complex by $8.8 \mathrm{kcal} / \mathrm{mol}$.

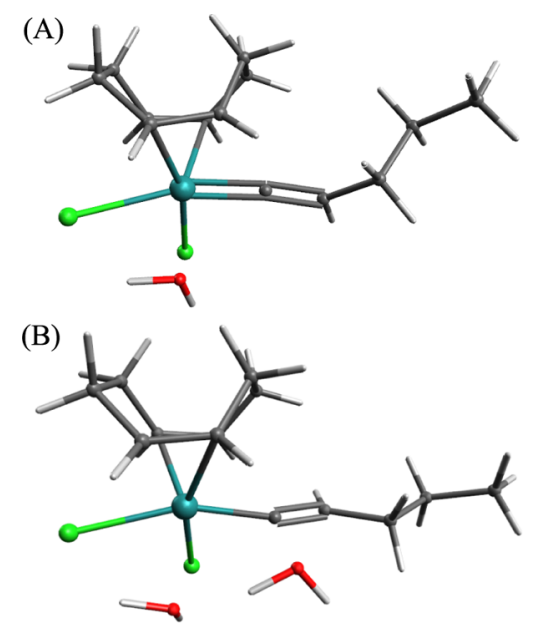

Figure 2. Three-dimensional (3D) models of intermediates (A) VI in open conformation with a coordinated water molecule and (B) transition state (TS) to produce $\mathbf{X I}$.

As a result of this coordination, the $\alpha$ carbon becomes available for attack by another water molecule, which requires an energy of activation of $17.0 \mathrm{kcal} / \mathrm{mol}$. At this stage, the formation of XI is incomplete because the hydrogen atom of water is still not bonded to the ruthenium metal center (Figure 2B). To achieve this, the system should change its multiplicity from a singlet to a triplet. This type of transition is usually forbidden, unless the triplet and the singlet potential energy surfaces come close in energy and the system benefits from spin-orbit coupling effect. ${ }^{72}$ The singlet and triplet potential surfaces were found to cross and the energy barrier for the $S \rightarrow$ $\mathrm{T}$ transition was determined to be $8.5 \mathrm{kcal} / \mathrm{mol}$. The spin crossing transition results in the dissociation of one chloride ligand from the metal complex. However, the proton transfer needed to complete the formation of XI had an unexpectedly high energy $(>20 \mathrm{kcal} / \mathrm{mol})$. Therefore, the formation of this complex was deemed improbable.
In light of this finding, the proposed mechanism shown in Scheme 6 needed to be adjusted, producing Scheme 7. The loss of chloride leaves the catalyst in a tetrahedral geometry (XIII), which can react with the aldehyde in an aldol fashion, forming XIV. The last transformation required to yield the products is the association of the chloride back onto the catalyst and the proton transfer onto the olefin. The energy barrier of the aldol step is estimated to 16.0 and $14.6 \mathrm{kcal} / \mathrm{mol}$ for the formation of $(R, S)$-XIV and $(S, S)$-XIV, respectively. The resulting intermediate XIV, illustrated in 3D in Scheme 7, shows that the atoms that will be eliminated in the subsequent stage of the reaction lie in the same plane (torsion angle $=178^{\circ}$ ). This conformation is favorable for an $\mathrm{E}_{2}$ elimination of water to produce $\mathbf{X V}$.

Deuterium-Labeling Experiments. To support the mechanistic hypothesis shown in Scheme 7, a series of isotope-labeling experiments were performed. The coupling between benzaldehyde and ${ }^{2} \mathrm{H}$-1-decyne resulted in the desired product with scrambling of proton isotope information for the hydrogen bonded to $\mathrm{C}_{\beta}$ (Scheme $8 \mathrm{~A}$ ) but not on the hydrogen bonded to $\mathrm{C}_{\alpha}$. This experiment supports the hypothesis that the elimination step proceeds as described in Scheme 7, which allows proton scrambling on $\mathrm{C}_{\beta}$, unlike Scheme 6 , where the proton of the 1-decyne is retained throughout the reaction.

In our previous report on this ruthenium catalyst, ${ }^{23}$ the reaction of benzaldehyde with 1-decyne in the presence of deuterated water, but without $\mathrm{CuCl}_{2}$ or $\mathrm{LiCl}$, resulted in no incorporation of deuterium in the final product (Scheme 8B). However, when the same experiment was repeated with $\mathrm{LiCl}$, a small incorporation of deuterium in the olefin product was noticed (Scheme 8C). According to the mechanism in Scheme 7 , a small amount of deuterated olefin would be produced both with and without $\mathrm{LiCl}$. Puzzled by these results, we re-examined the role of additives in the reaction.

Based on the results from the deuterium-labeling experiments shown in Scheme 8B,C, it can be concluded that the presence of $\mathrm{LiCl}$ and $\mathrm{CuCl}_{2}$ promotes the mechanism described in Scheme 7, whereas in the absence of these additives, a different elimination reaction mechanism is in effect. For example, the formation of carbon monoxide can release the product olefin with the retention of 1-decyne proton (marked in red in Scheme 9A). Conversely, metals like lithium or copper may chelate the aldol product XIV rendering the proton on $\mathrm{C}_{\beta}$ more acidic and leading to the elimination of water containing a proton from the alkyne (Scheme 9B).

This difference is supported by the difference in atomic charges of this proton: +0.22 and +0.14 with and without $\mathrm{LiCl}$, respectively. The change in acidity is also indicated by the electrostatic surface potential map (Figure 3), which shows how the presence of $\mathrm{LiCl}$ shifts the electron density.

Catalyst Deactivation. The second to last steps of the reaction mechanism in Scheme 7 is a decarbonylation. The loss of the terminal alkyne carbon as $\mathrm{CO}$ through a rutheniumvinylidene complex has previously been reported, among others, for the intramolecular reaction in Scheme $1^{42}$ and for the $\mathrm{Ru}(\mathrm{II})$-mediated $\mathrm{C}-\mathrm{C}$ cleavage of phenylacetylene by water into toluene and a $\mathrm{Ru}(\mathrm{II})-\mathrm{CO}$ complex. ${ }^{68}$ The analysis of the reaction mixture by IR spectroscopy revealed multiple $\mathrm{Ru}-\mathrm{CO}$ stretches for the reaction with $\mathrm{H}_{2} \mathrm{O}$ and a mixture of $\mathrm{Ru}-\mathrm{CO}$ and $\mathrm{Ru}-\mathrm{C}^{18} \mathrm{O}$ bands when the reaction was carried out in the presence of $\mathrm{H}_{2}{ }^{18} \mathrm{O}$, indicative of more than one $\mathrm{CO}$ occupying the coordination sites of ruthenium. The mechanism of decarbonylation of metal-acyl complexes often involves 
Scheme 7. Revised Mechanism through an Aldol-type Condensation, Highlighting the 3D Structure of Intermediate XIV ${ }^{a}$

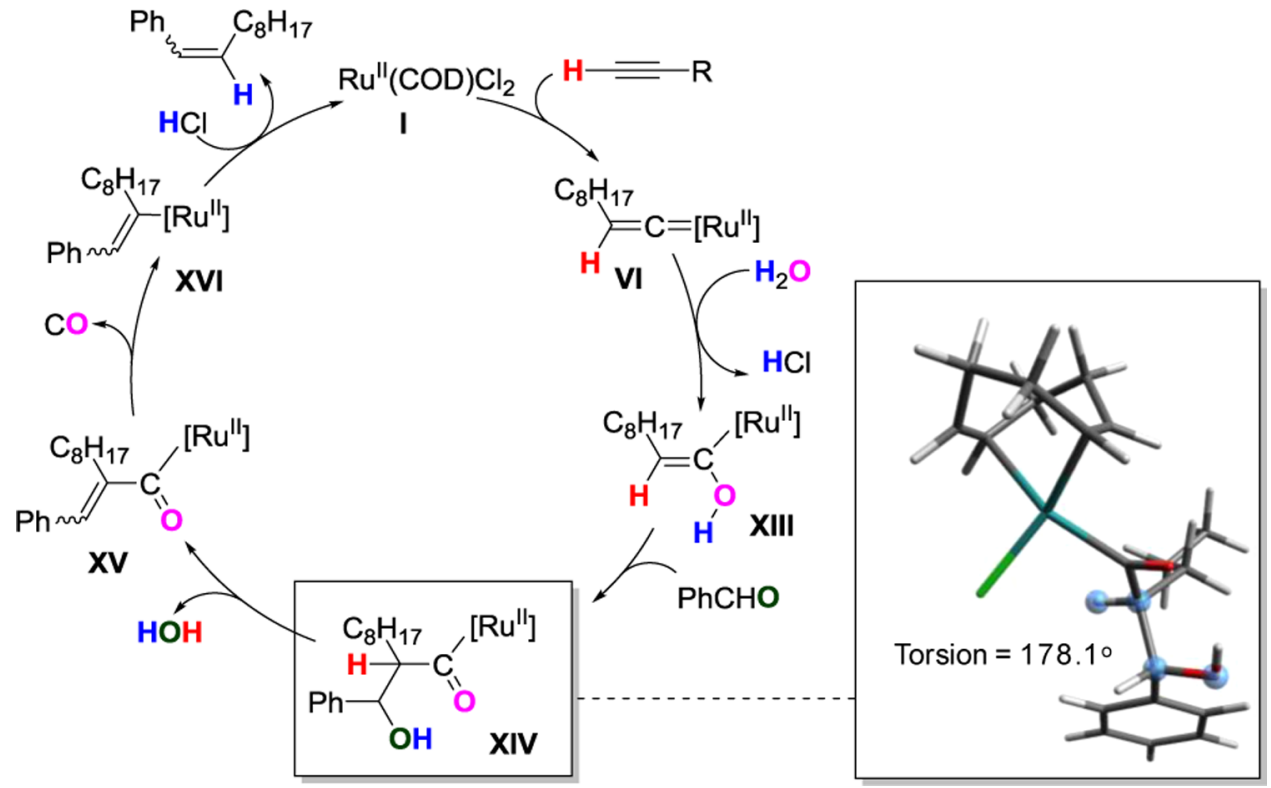

${ }^{a_{T}}$ The atoms that will be undergo elimination to produce $\mathrm{XV}$ are shown are blue spheres, they are anti-periplanar, so an $\mathrm{E}_{2}$ would be possible.

Scheme 8. (A) Reaction of Benzaldehyde with ${ }^{2}$ H-1-Decyne and Benzaldehyde, (B) Reaction of Benzaldehyde with 1Decyne in the Presence of $\mathrm{D}_{2} \mathrm{O}$, No Other Additive, and (C) Reaction of Benzaldehyde with 1-Decyne in the Presence of $\mathrm{D}_{2} \mathrm{O}$, Optimized Conditions

(A)

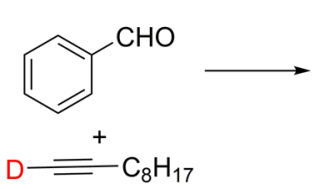

(B)
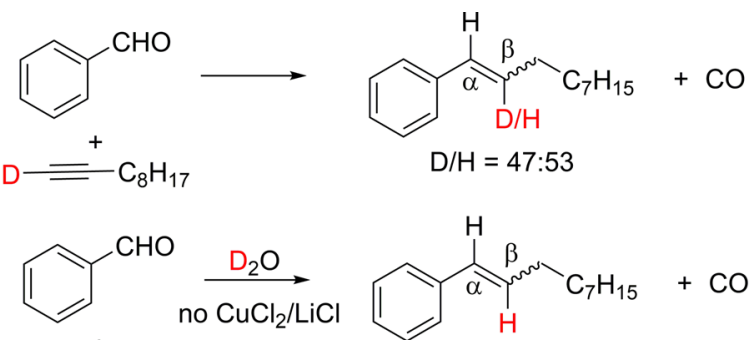

(C)
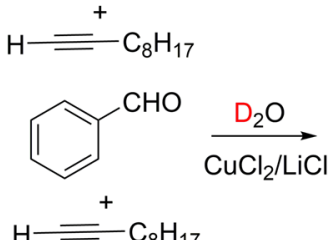<smiles>O=C[C+]CC=Cc1ccccc1</smiles>

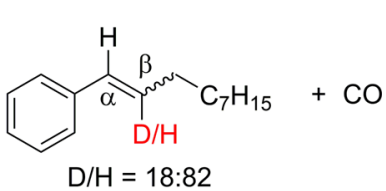

transfer of carbon monoxide directly onto the metal ${ }^{23,73}$ and its subsequent release through ligand exchange. A potential energy scan of the loss of CO shows that this elimination is not energetically favorable (Figure S1). Clearly, the $\pi$-backbonding of carbon monoxide to ruthenium is strong, blocking the metal coordination sites, and leading to catalyst deactivation. This finding tentatively explains the requirement of a high catalyst loading $(10 \mathrm{~mol} \% \mathrm{Ru})$ for the optimized reaction conditions.

Final Mechanism. To summarize our findings on this coupling reaction, the main steps of the final proposed mechanism as well as their relative energies are shown in Figure 4. First, the catalyst forms a ruthenium-vinylidene intermediate VI, which can take several ligand configurations. The open configuration of VI, stabilized by a water molecule, reacts with another water molecule to produce the hydroxyvinyl-RuII species XIII. This intermediate can undergo a spin state transition from singlet to triplet, which is its more stable configuration. In the presence of an aldehyde, hydroxyvinyl- $\mathrm{Ru}^{\mathrm{II}}$ reacts in an aldol fashion to yield $(R, S)$-XIV and $(S, S)$-XIV, which will generate the cis- and the trans-olefin products, respectively, at the end of the catalytic cycle. The next steps of the reaction differ depending on whether $\mathrm{LiCl}$ and/or $\mathrm{CuCl}_{2}$ is added. In fact, in the absence of these additives (marked in blue

Scheme 9. Elimination Step of Aldol-type Mechanism in the Absence (A) and Presence (B) of $\mathrm{LiCl}_{\text {or }} \mathrm{CuCl}_{2}$

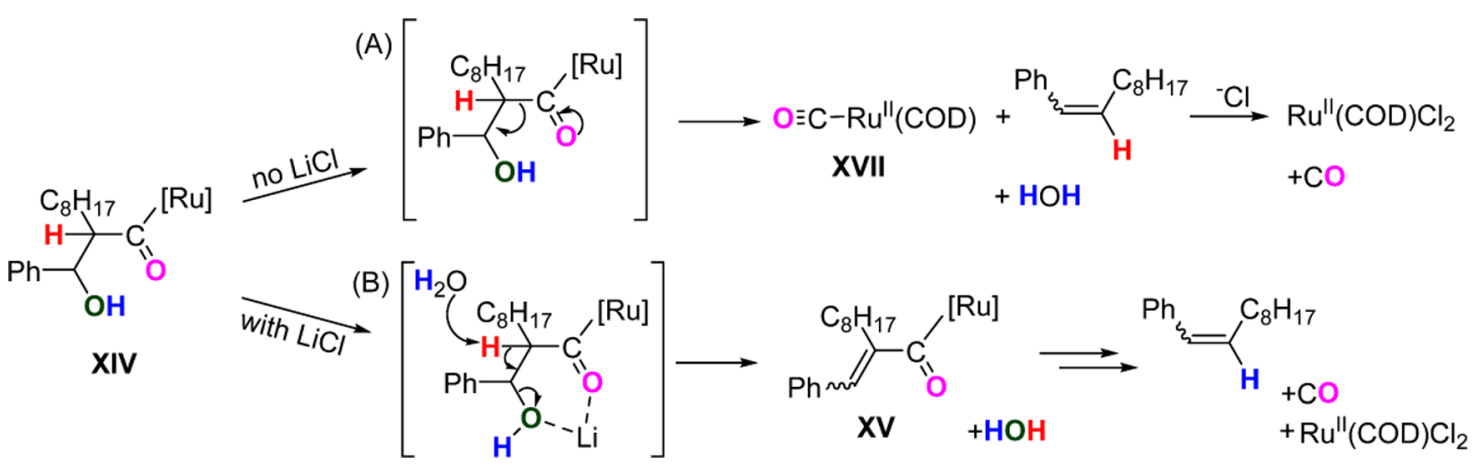



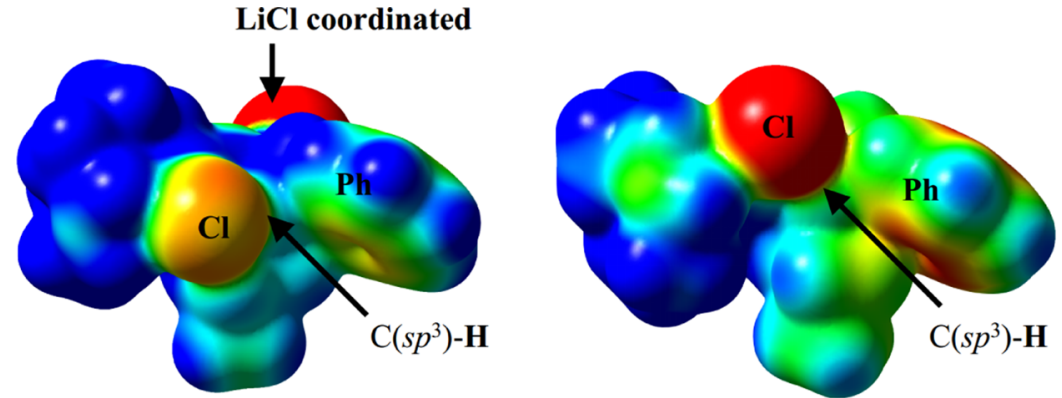

$+20 \mathrm{kcal} / \mathrm{mol}$

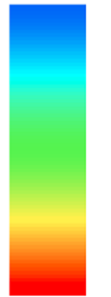

$-20 \mathrm{kcal} / \mathrm{mol}$

Figure 3. Electrostatic potential of XIV plotted on an iso density surface of the electron density set to $0.002 \mathrm{e} / \mathrm{bohr} \mathrm{P}^{3}$ : (left) with $\mathrm{LiCl}$ and (right) without $\mathrm{LiCl}$ coordination.

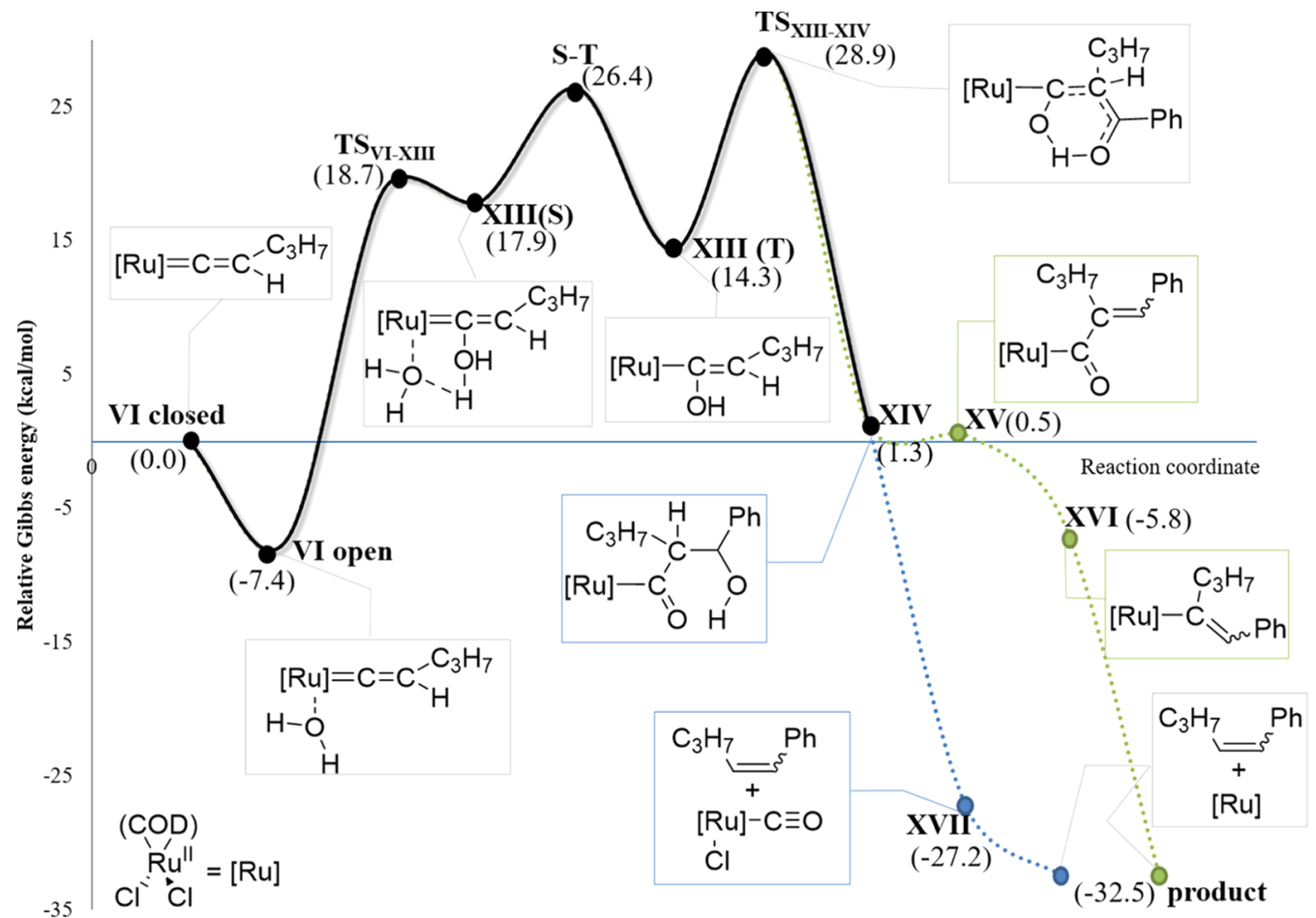

..... Without $\mathrm{LiCl} / \mathrm{CuCl} 2 \quad \ldots$. In presence of $\mathrm{LiCl} / \mathrm{CuCl} 2$

Figure 4. Changes in Gibbs energy for the reaction mechanism shown in Scheme 7. For clarity, the reaction pathway leading to only the cis product olefin is shown. The blue curve displays the energy changes for Scheme 9A, whereas the green curves show the energy changes for Scheme 9B. Dashed curves mean only ground-state structures were computed.

in Figure 4), intermediate XIV releases the product olefins and forms a strong bond with a newly formed carbon monoxide (XVII). The loss of CO allows the regeneration of the catalyst, but the high energy required to release this ligand leads to partial catalyst deactivation. On the other hand, $\mathrm{LiCl}$ and/or $\mathrm{CuCl}_{2}$ additives act as Lewis acids, which can stabilize the aldol product XIV, rendering the proton on $\mathrm{C}_{\beta}$ more acidic. This stabilization favors the elimination of a water molecule producing intermediate XV (marked in green in Figure 4). The loss of the terminal alkyne carbon as carbon monoxide, yielding XVI, and the release of product olefins regenerate the catalyst and complete the catalytic cycle.

\section{CONCLUSIONS}

We have reported in-depth computational studies to elucidate the mechanism of a ruthenium-catalyzed decarbonylative coupling reaction between an aromatic aldehyde and terminal alkyne to produce olefins supported by experimental data.
Several possibilities were investigated before the formulation of the final proposed mechanism (Scheme 7). Control experiments unequivocally refute our initially proposed mechanism ${ }^{23}$ of the reaction being initiated by the aldehyde $\mathrm{C}-\mathrm{H}$ activation and the subsequent decarbonylation of aldehyde acyl carbon as CO. The only other chemically feasible pathway is the initial activation of the terminal alkyne to form a rutheniumvinylidene complex, which can produce olefin products either by a $[2+2]$-cycloaddition or an aldol-type condensation. The combined experimental and computational data suggest that this reaction proceeds via an aldol-type pathway and the concomitant loss of the terminal alkyne carbon as carbon monoxide, thus closing this mechanistic debate. The density functional theory (DFT) calculations, supported by the IR data, implicate the catalyst deactivation as a result of strong binding with $\mathrm{CO}$, as has been proposed for other ruthenium-based catalytic systems. ${ }^{74}$ The effect of $\mathrm{LiCl}$ and $\mathrm{CuCl}_{2}$ additives on the reaction mechanism has been explained using the 
electrostatic potential maps and isotope-labeling experiments. This new mechanistic proposal highlights the complexity of these ruthenium catalysts that operate in such different reaction conditions leading to distinct mechanisms.

\section{EXPERIMENTAL SECTION}

Computational Methodology. All calculations were performed using ORCA. ${ }^{75}$ Optimizations and frequency calculations were performed using the hybrid exchange correlation DFT method PBE0. ${ }^{76}$ The def2-SVP basis set was used for all atoms, except ruthenium, chlorine, oxygen, lithium, and carbon, directly involved in the reaction for which def2TZVP was used. All structures were optimized in the gas phase. Preliminary calculations indicated that the inclusion of solvent (toluene) using the polarizable continuum model did not affect the results. The dispersion was also expected to only have a minor impact because we were not investigating molecular properties such as NMR shifts or crystal packing nor studying the systems bound by weak van der Waals forces. The reactants used to model this reaction were benzaldehyde and pent-1-yne. Note that the alkane chain $\mathrm{C}_{8} \mathrm{H}_{17}$ of 1-decyne (used in all experiments) was reduced in size to three carbons. The vibrational modes calculations were performed to verify that all stationary points have the appropriate number of imaginary frequencies (none for ground state, one for TSs). The validity of TSs was verified by following the corresponding normal mode and relaxing the resulting structure to obtain the products and reactants of each step. The energies reported are Gibbs energies, where the entropic component of the energy was obtained from harmonic vibrational frequencies. The minimum energy crossing point for the $S \rightarrow T$ transition was determined using the SurfCrossOpt feature in ORCA.

\section{ASSOCIATED CONTENT}

\section{S Supporting Information}

The Supporting Information is available free of charge on the ACS Publications website at DOI: 10.1021/acsomega.7b01877.

Experimental details and materials, Cartesian coordinates of all stationary points, energy values, plot of the potential energy surface scan for the stretching of ruthenium-carbon monoxide bond in compound XVII (PDF)

\section{AUTHOR INFORMATION}

\section{Corresponding Authors}

*E-mail: cj.li@mcgill.ca (C.-J.L.).

*E-mail: nicolas.moitessier@mcgill.ca (N.M.).

ORCID

Chao-Jun Li: 0000-0002-3859-8824

Nicolas Moitessier: 0000-0001-6933-2079

\section{Present Addresses}

${ }^{\S}$ IntelliSyn Pharma Inc, 7171 Rue Frederick Banting, SaintLaurent, Quebec, Canada H4S 1Z9 (F.Z.).

${ }^{\ddagger}$ Highway 60 and 123, Bartlesville, Oklahoma 74003, United States (S.K.)

${ }^{\dagger}$ AstraZeneca R\&D Pepparedsleden 1, Mölndal 431 83, Sweden (A.T.).

Notes

The authors declare no competing financial interest.

\section{ACKNOWLEDGMENTS}

We are grateful to the Canada Research Chair (Tier 1) Foundation (to C.-J.L.), the FRQNT, NSERC and CFI for their support of our research (N.M. and C.-J.L.). S.K. would like to thank Dr. Lu Li, Dr. Fred Morin, and Nadim K. Saadeh for their assistance with head-space GC analysis, ${ }^{2} \mathrm{H}$ NMR spectroscopy, and HR-APCI experiments, respectively.

\section{REFERENCES}

(1) Shen, Y. New Synthetic Methodologies for Carbon-Carbon Double Bond Formation. Acc. Chem. Res. 1998, 31, 584-592.

(2) Shah, S.; Protasiewicz, J. D. Phospha-variations' on the themes of Staudinger and Wittig: phosphorus analogs of Wittig reagents. Coord. Chem. Rev. 2000, 210, 181-201.

(3) Charette, A. B.; Berthelette, C.; St-Martin, D. An expedient approach to E,Z-dienes using the Julia olefination. Tetrahedron Lett. 2001, 42, 5149-5153.

(4) Claridge, T. D. W.; Davies, S. G.; Lee, J. A.; Nicholson, R. L.; Roberts, P. M.; Russell, A. J.; Smith, A. D.; Toms, S. M. Highly (E)Selective Wadsworth-Emmons Reactions Promoted by Methylmagnesium Bromide. Org. Lett. 2008, 10, 5437-5440.

(5) Liu, D.-N.; Tian, S.-K. Stereoselective Synthesis of Polysubstituted Alkenes through a Phosphine-Mediated Three-Component System of Aldehydes, alpha-Halo Carbonyl Compounds, and Terminal Alkenes. Chem. Eur. J. 2009, 15, 4538-4542.

(6) Kolodiazhnyi, O. I. Phosphorus Ylides: Chemistry and Applications in Organic Chemistry; Wiley-VCH: New York, 1999.

(7) Dumeunier, R; Markó, I. E. Modern Carbonyl Olefination; WileyVCH: Weinheim, Germany, 2004.

(8) Wittig, G.; Geissler, G. Zur Reaktionsweise des Pentaphenylphosphors und einiger Derivate. Justus Liebigs Ann. Chem. 1953, 580, 44-57.

(9) Maryanoff, B. E.; Reitz, A. B. The Wittig olefination reaction and modifications involving phosphoryl-stabilized carbanions. Stereochemistry, mechanism, and selected synthetic aspects. Chem. Rev. 1989, 89, 863-927.

(10) Still, W. C.; Gennari, C. Direct synthesis of Z-unsaturated esters. A useful modification of the Horner-Emmons olefination. Tetrahedron Lett. 1983, 24, 4405-4408.

(11) Peterson, D. J. Carbonyl olefination reaction using silylsubstituted organometallic compounds. J. Org. Chem. 1968, 33, 780784.

(12) Corey, E. J.; Enders, D.; Bock, M. G. A simple and highly effective route to $\mathrm{R}$, alpha,beta-unsaturated aldehydes. Tetrahedron Lett. 1976, 7-10.

(13) Negishi, E.-I.; Huang, Z.; Wang, G.; Mohan, S.; Wang, C.; Hattori, H. Recent Advances in Efficient and Selective Synthesis of Di-, Tri-, and Tetrasubstituted Alkenes via Pd-Catalyzed AlkenylationCarbonyl Olefination Synergy. Acc. Chem. Res. 2008, 41, 1474-1485.

(14) Alcaide, B.; Almendros, P.; Luna, A. Grubbs' rutheniumcarbenes beyond the metathesis reaction: less conventional nonmetathetic utility. Chem. Rev. 2009, 109, 3817-3858.

(15) Vehlow, K.; Wang, D.; Buchmeiser, M. R.; Blechert, S. Alternating copolymerizations using a Grubbs-type initiator with an unsymmetrical, chiral N-heterocyclic carbene ligand. Angew. Chem., Int. Ed. 2008, 47, 2615-2618.

(16) Clark, D. A.; Clark, J. R.; Diver, S. T. Alkenol-Alkyne Cross Metathesis. Org. Lett. 2008, 10, 2055-2058.

(17) Trnka, T. M.; Grubbs, R. H. The development of L2X2Ru = CHR olefin metathesis catalysts: An organometallic success story. Acc. Chem. Res. 2001, 34, 18-29.

(18) Nguyen, S. T.; Johnson, L. K.; Grubbs, R. H.; Ziller, J. W. RingOpening Metathesis Polymerization (Romp) of Norbornene by a Group-VIII Carbene Complex in Protic Media. J. Am. Chem. Soc. 1992, 114, 3974-3975.

(19) Chauvin, Y.; Gilbert, B.; Guibard, I. Catalytic Dimerization of Alkenes by Nickel-Complexes in Organochloroaluminate Molten-Salts. J. Chem. Soc., Chem. Commun. 1990, 23, 1715-1716. 
(20) Schrock, R. R.; Meakin, P. Pentamethyl complexes of niobium and tantalum. J. Am. Chem. Soc. 1974, 96, 5288-5290.

(21) Crabtree, R. H. Homogeneous Catalysis. In The Organometallic Chemistry of the Transition Metals; John Wiley \& Sons, Inc., 2005; pp 235-273.

(22) Trost, B. M.; Ball, Z. T. Alkyne Hydrosilylation Catalyzed by a Cationic Ruthenium Complex: Efficient and General Trans Addition. J. Am. Chem. Soc. 2005, 127, 17644-17655.

(23) Guo, X.; Wang, J.; Li, C.-J. An Olefination via RutheniumCatalyzed Decarbonylative Addition of Aldehydes to Terminal Alkynes. J. Am. Chem. Soc. 2009, 131, 15092-15093.

(24) Kondo, T.; Akazome, M.; Tsuji, Y.; Watanabe, Y. Ruthenium Complex Catalyzed Intermolecular Hydroacylation and Transhydroformylation of Olefins with Aldehydes. J. Org. Chem. 1990, 55, 12861291.

(25) Kondo, T.; Hiraishi, N.; Morisaki, Y.; Wada, K.; Watanabe, Y.; Mitsudo, T.-A. First Intermolecular Hydroacylation of 1,3-Dienes with Aldehydes Catalyzed by Ruthenium. Organometallics 1998, 17, 21312134.

(26) Williams, V. M.; Leung, J. C.; Patman, R. L.; Krische, M. J. Hydroacylation of 2-butyne from the alcohol or aldehyde oxidation level via ruthenium catalyzed $\mathrm{C}-\mathrm{C}$ bond forming transfer hydrogenation. Tetrahedron 2009, 65, 5024-5029.

(27) Ko, S.; Na, Y.; Chang, S. A Novel Chelation-Assisted Hydroesterification of Alkenes via Ruthenium Catalysis. J. Am. Chem. Soc. 2002, 124, 750-751.

(28) Domazetis, G.; Tarpey, B.; Dolphin, D.; Jame, B. R. Catalytic Decarbonylation of Aldehydes using Ruthenium(II) Porphyrin Systems. J. Chem. Soc., Chem. Commun. 1980, 939-940.

(29) Bag, N.; Choudhury, S. B.; Lahiri, G. K.; Chakravorty, A. A Novel Zwitterionic ortho-Metallated Ruthenium(II) Phenolate. J. Chem. Soc., Chem. Commun. 1990, 1626-1627.

(30) Burns, R. M.; Hubbard, J. L. Alkyne Activation by Electrophilic [ $(\mathrm{q}-\mathrm{CsMes}) \mathrm{Ru}(\mathrm{NO})(\mathrm{R})]+(\mathrm{R}=\mathrm{Me}, \mathrm{Ph}, \mathrm{p}$-Tolyl $)$ Fragments: betaMigratory Insertion, Isomerization, and Metallacycle Formation. J. Am. Chem. Soc. 1994, 116, 9514-9520.

(31) Doucet, H.; Martin-Vaca, B.; Bruneau, C.; Dixneuf, P. H. General Synthesis of (Z)-Alk-1-en-1-yl Esters via RutheniumCatalyzed anti-Markovnikov trans-Addition of Carboxylic Acids to Terminal Alkynes. J. Org. Chem. 1995, 60, 7247-7255.

(32) Kawatsura, M.; Namioka, J.; Kajita, K.; Yamamoto, M.; Tsuji, H.; Itoh, T. Ruthenium-Catalyzed Regio- and Stereoselective Addition of Carboxylic Acids to Aryl and Trifluoromethyl Group Substituted Unsymmetrical Internal Alkynes. Org. Lett. 2011, 13, 3285-3287.

(33) Cadierno, V.; Francos, J.; Gimeno, J. Ruthenium(IV)-Catalyzed Markovnikov Addition of Carboxylic Acids to Terminal Alkynes in Aqueous Medium. Organometallics 2011, 30, 852-862.

(34) Willis, M. C. Transition Metal Catalyzed Alkene and Alkyne Hydroacylation. Chem. Rev. 2010, 110, 725-748.

(35) Trost, B. M. The atom economy-a search for synthetic efficiency. Science 1991, 254, 1471-1477.

(36) Trost, B. M. On inventing reactions for atom economy. Acc. Chem. Res. 2002, 35, 695-705.

(37) Sakai, K.; Ide, J.; Oda, O.; Nakamura, N. Synthetic studies on prostanoids 1 synthesis of methyl 9-oxoprostanoate. Tetrahedron Lett. 1972, 13, 1287-1290.

(38) Milstein, D. Isolation of cis-hydridoacylrhodium(III) complexes not stabilized by chelation. Reductive elimination and decarbonylation. Organometallics 1982, 1, 1549-1551.

(39) Suggs, J. W. Isolation of a stable acylrhodium(III) hydride intermediate formed during aldehyde decarbonylation. Hydroacylation. J. Am. Chem. Soc. 1978, 100, 640-641.

(40) Beck, C. M.; Rathmill, S. E.; Park, Y. J.; Chen, J.; Crabtree, R. H.; et al. Aldehyde Decarbonylation Catalysis under Mild Conditions. Organometallics 1999, 18, 5311-5317.

(41) Yang, L.; Guo, X.; Li, C.-J. The First Decarbonylative Coupling of Aldehydes and Norbornenes Catalyzed by Rhodium. Adv. Synth. Catal. 2010, 352, 2899-2904.
(42) Varela, J. A.; González-Rodríguez, C.; Rubín, S. G.; Castedo, L.; Saá, C. Ru-Catalyzed Cyclization of Terminal Alkynals to Cycloalkenes. J. Am. Chem. Soc. 2006, 128, 9576-9577.

(43) Zhang, J. S.; Shen, W.; Liu, R. Q.; Yu, Y. Q.; Wu, H. L.; Li, M. DFT Study on Ru-II-Catalyzed Cyclization of Terminal Alkynals to Cycloalkenes. Int. J. Quantum Chem. 2009, 109, 679-687.

(44) Batuecas, M.; Esteruelas, M. A.; García-Yebra, C.; Oñate, E. Osmium-Centered Oxetylidene: Formation and Cleavage. Organometallics 2012, 31, 8079-8081.

(45) Batuecas, M.; Esteruelas, M. A.; Garcia-Yebra, C.; GonzalezRodrı́guez, C.; Oñate, E.; Saá, C. Ruthenium Hydroxycarbenes as Key Intermediates in Cycloisomerization and Decarbonylative Cyclization of Terminal Alkynals. Organometallics 2014, 33, 3474-3480.

(46) Allen, C. L.; Williams, J. M. J. Ruthenium-Catalyzed Alkene Synthesis by the Decarbonylative Coupling of Aldehydes with Alkynes. Angew. Chem., Int. Ed. 2010, 49, 1724-1725.

(47) Schmidt, Y.; Breit, B. Stereoselective Synthesis of Trisubstituted Olefins by a Directed Allylic Substitution Strategy. Chem. Eur. J. 2011, 17, 11780-11788.

(48) Tsuji, J.; Ohno, K. Organic Syntheses by Means of Noble Metal Compounds XXXI. Carbonylation of Olefins and Decarbonylation of Acyl Halides and Aldehydes. Tetrahedron Lett. 1965, 6, 3969-3971.

(49) Ríos, I. d. 1.; Tenorio, M. J.; Puerta, M. C.; Valerga, P. Alternative Mechanisms of the Alkyne to Vinylidene Isomerization Promoted by Half-Sandwich Ruthenium Complexes. X-ray Crystal Structures of $[\mathrm{Cp} * \mathrm{RuCCHCOOMe}($ dippe $)][\mathrm{BPh} 4]$ and $\left[\mathrm{Cp}^{*} \mathrm{RuH}-\right.$ $(\mathrm{C} \vdots \mathrm{CCOOMe})(\mathrm{dippe})][\mathrm{BPh} 4]$ (dippe $=1,2$-bis(diisopropylphosphino)ethane; $\left.\mathrm{Cp}^{*}=\mathrm{C} 5 \mathrm{Me} 5\right)$. J. Am. Chem. Soc. 1997, 119, 6529-6538.

(50) Wakatsuki, Y.; Koga, N.; Yamazaki, H.; Morokuma, K. Acetylene .pi--Coordination, Slippage to sigma.-Coordination, and 1,2-Hydrogen Migration Taking Place on a Transition Metal. The case of a $\mathrm{Ru}(\mathrm{II})$ Complex as Studied by Experiment and ab Initio Molecular Orbital Simulations. J. Am. Chem. Soc. 1994, 116, 8105-8111.

(51) Bruneau, C.; Dineuf, P. H. Metal Vinylidenes in Catalysis. Acc. Chem. Res. 1999, 32, 311-323.

(52) Wakatsuki, Y. Mechanistic aspects regarding the formation of metal vinylidenes from alkynes and related reactions. J. Organomet. Chem. 2004, 689, 4092-4109.

(53) Bruneau, C.; Dixneuf, P. H. Metal Vinylidenes and Allenylidenes in Catalysis: Applications in Anti-Markovnikov Additions to Terminal Alkynes and Alkene Metathesis. Angew. Chem., Int. Ed. 2006, 45, 2176-2203.

(54) Bustelo, E.; Jimenez-Tenorio, M.; Puerta, M. C.; Valerga, P. Hydrido(3-hydroxyalkynyl) Complexes as Intermediates in the Activation of Propargyl Alcohol Derivatives by $\left[\mathrm{Cp}^{*} \mathrm{RuCl}(\right.$ dippe $\left.)\right]$ $\left[\mathrm{Cp}^{*}=\mathrm{C} 5 \mathrm{Me} 5\right.$, dippe $=1$,2-bis (diisopropylphosphanyl)ethane $]$. Eur. J. Inorg. Chem. 2001, 9, 2391-2398.

(55) Baya, M.; Crochet, P.; Esteruelas, M. A.; Lopez, A. M.; Modrego, J.; Onate, E. Formation of cationic half-sandwich osmiumvinylidene complexes from [O-S(eta(5)-C5H5)((PPr3)-Pr-i)2](+) and terminal alkynes. Organometallics 2001, 20, 4291-4294.

(56) Otsuka, M.; Tsuchida, N.; Ikeda, Y.; Kimura, Y.; Mutoh, Y.; Ishii, Y.; Takano, K. DFT Study of Internal Alkyne-to-Disubstituted Vinylidene Isomerization in $[\mathrm{CpRu}(\mathrm{PhC}$ equivalent to $\mathrm{CAr})(\mathrm{dppe})]$ (+). J. Am. Chem. Soc. 2012, 134, 17746-17756.

(57) Murakami, M.; Ubukata, M.; Ito, Y. Ruthenium-Catalyzed Coupling of Unactivated Olefins with Unactivated Alkynes. Tetrahedron Lett. 1998, 39, 7361-7364.

(58) Bigeault, J.; Giordano, L.; Buono, G. [2+1] Cycloadditions of Terminal Alkynes to Norbornene Derivatives Catalyzed by Palladium Complexes with Phosphinous Acid Ligands. Angew. Chem., Int. Ed. 2005, 44, 4753-4757.

(59) Barrett, A. G. M.; Brock, C. P.; Sturgess, M. A. Application of Pentacarbonylchromium Carbenes in Beta-Lactam Synthesis Preparation and X-Ray Crystallographic Study of (1-Methyl-4Phenyl-3(E)-(Phenylmethylene )-Azetidinylidene)Pentacarbonylchromium. Organometallics 1985, 4, 1903-1905. 
(60) Barrett, A. G. M.; Sturgess, M. A. [2+2] Cycloaddition Reactions of Cationic Iron Vinylidene Complexes. Tetrahedron Lett. 1986, 27, 3811-3814.

(61) Barrett, A. G. M.; Sturgess, M. A. Cationic Iron Vinylidene Complexes in Bicyclic Beta-Lactam Synthesis. J. Org. Chem. 1987, 52, 3940-3941.

(62) Barrett, A. G. M.; Mortier, J.; Sabat, M.; Sturgess, M. A. Iron(II) Vinylidenes and Chromium Carbene Complexes in Beta-Lactam Synthesis. Organometallics 1988, 7, 2553-2561.

(63) Gamble, A. S.; Birdwhistell, K. R.; Templeton, J. L. Formation of a Tungsten Vinylvinylidene Complex from Addition of Alkyne to (Dppe) $(\mathrm{Oc}) 3 \mathrm{w}=\mathrm{C}=$ Chph. Organometallics 1988, 7, 1046-1050.

(64) Kostić, N. M.; Fenske, R. F. Molecular Orbital Study of Bonding, Conformations, and Reactivity of Transition-Metal Complexes Containing Unsaturated Organic Ligands. Electrophilic and Nucleophilic Additions to Acetylide, Vinylidene, Vinyl, and Carbene Ligands. Organometallics 1982, 1, 974-982.

(65) Davison, A.; Selegue, J. P. Stepwise Reduction of an EthynylIron Complex to a Neopentylidene Complex. J. Am. Chem. Soc. 1980, $102,2455-2456$.

(66) Davison, A.; Selegue, J. P. Stable Dimethyl, Methyl, and Unsubstituted Vinylidene Complexes. J. Am. Chem. Soc. 1978, 100, $7763-7765$.

(67) Tokunaga, M.; Suzuki, T.; Koga, N.; Fukushima, T.; Horiuchi, A.; Wakatsuki, Y. Ruthenium-Catalyzed Hydration of 1-Alkynes to Give Aldehydes: Insight into anti-Markovnikov Regiochemistry. J. Am. Chem. Soc. 2001, 123, 11917-11924.

(68) Bianchini, C.; Casares, J. A.; Peruzzini, M.; Romerosa, A.; Zanobini, F. The Mechanism of the Ru-Assisted C-C Bond Cleavage of Terminal Alkynes by Water. J. Am. Chem. Soc. 1996, 118, 45854594.

(69) Belluco, U.; Bertani, R.; Meneghetti, F.; Michelin, R. A.; Mozzon, M. Evidence for platinum(II)-vinylidene complexes and their reactions with water to give hydrocarbons and olefins. $J$. Organomet. Chem. 1999, 583, 131-135.

(70) Bruce, M. I.; Swincer, A. G. Cyclopentadienyl-ruthenium and -osmium chemistry. X. Reactions of vinylidene complexes with alcohols and water: syntheses of alkoxy(alkyl)carbene, acyl and alkyl complexes. Aust. J. Chem. 1980, 33, 1471-1483.

(71) Tokunaga, M.; Wakatsuki, Y. The first anti-Markovnikov hydration of terminal alkynes: Formation of aldehydes catalyzed by a ruthenium(II)/phosphane mixture. Angew. Chem., Int. Ed. 1998, 37, 2867-2869.

(72) Abd-El-Aziz, A. S.; Carraher, C. E.; Harvey, P. D.; Pittman, C. U.; Zeldin, M. Macromolecules Containing Metal and Metal-Like Elements, Photophysics and Photochemistry of Metal-Containing Polymers; Wiley, 2010.

(73) Wang, J.; Guo, X.; Li, C.-J. Iridium as a general catalyst for the decarbonylative addition of aldehydes to alkynes. J. Organomet. Chem. 2011, 696, 211-215.

(74) Kärkäs, M. D.; Åkermark, T.; Chen, H.; Sun, J.; Åkermark, B. A Tailor-Made Molecular Ruthenium Catalyst for the Oxidation of Water and Its Deactivation through Poisoning by Carbon Monoxide. Angew. Chem., Int. Ed. 2013, 125, 4283-4287.

(75) Neese, F. The ORCA program system. Wiley Interdiscip. Rev.: Comput. Mol. Sci. 2012, 2, 73-78.

(76) Adamo, C.; Barone, V. Toward reliable density functional methods without adjustable parameters: The PBE0 model. J. Chem. Phys. 1999, 110, 6158-6170. 